\title{
Analisis Framing Pemberitaan Habib Rizieq Shihab selama di RS Bogor Terkait Hasil Swab Tes
}

\author{
Rain Gunawan, Umaimah Wahid \\ Magister Ilmu Komunikasi, Universitas Budi Luhur \\ E-mail: raditya521@ gmail.com
}

DOI: https://doi.org/10.21107/ilkom.v15i1.9580

\begin{abstract}
ABSTRAK
Seiring dengan pesatnya perkembangan teknologi informasi seperti saat ini, informasi sangat mudah didapatkan dari berbagai sumber seperti berita online, media sosial hingga aplikasi pesan singkat. Cepatnya penyebaran informasi ini terkadang menimbulkan perbedaan persepsi dan sudut pandang informasi di masyarakat. Penelitian ini bertujuan untuk mengetahui bagaimana media membingkai dan mengkonstruk realitas pemberitaan tentang sosok Habib Rizieq Shihab (HRS) saat berada di RS Ummi Bogor. Review media yang penulis teliti adalah berita dari kompas.com dan nusadaily.com. Penelitian ini merupakan penelitian kualitatif dengan metode framing Robert Entman yang menitikberatkan pada bagaimana mendefinisikan masalah, apa / siapa penyebab masalah, keputusan moral yang terkandung dalam pemberitaan dan apa yang ditaw arkan untuk penyelesaiannya. Hasil penelitian menunjukkan bahwa kedua media memiliki gaya pemberitaan yang berbeda dalam memberitakan sosok HRS, dimana kompas.com membuat headline berita dengan judul yang cukup menarik namun tidak kontroversial, sedangkan nusadaily.com membuat judul yang sedikit vulgar dan cukup kontroversial. Isi pemberitaan kedua media juga menawarkan persepsi yang berbeda di masyarakat. Kompas.com mengungkap berita tersebut lebih detail terkait hak pasien dan kewajiban rumah sakit terhadap pasien, sedangkan nusadaily.com hanya sebatas membingkai pernyataan analis politik tanpa memperhatikan aspek hak pasien dan kewajiban rumah sakit terhadap pasien.
\end{abstract}

Kata Kunci: Framing Entman, framing media, hak pasien, kewajiban rumah sakit

\section{ABSTRACT}

Along with the rapid development of information technology as it is today, information is very easy to obtain from various sources such as online news, social media to short message applications. The rapid dissemination of this information sometimes causes different perceptions and points of view of information in society. This study aims to determine how a media frame and construct the reality of news about the figure of Habib Rizieq Shihab (HRS) while in RS Ummi Bogor. Media reviews that the author of the study are news from kompas.com and nusadaily.com. This research is a qualitative research using the Robert Entman framing method which focuses on how to define the problem, what / who causes the problem, the moral decisions contained in the news and what is offered for its resolution. The results showed that the two media had different news styles in reporting the HRS figure, where kompas.com made news headlines with titles that were quite interesting but not controversial, while nusadaily.com made titles that were a little vulgar and quite controversial. The news content of the two media also offers different perceptions in society. Kompas.com disclosed the news in more detail related to patient rights and hospital obligations towards patients, while nusadaily.com was only limited to framing a political analyst's statement without paying attention to aspects of patient rights and hospital obligations towards patients.

Keywords: Entman framing, media framing, patient rights, hospital obligations

\section{Cite this as:}

Gunawan, Rain \& Umaimah Wahid (2021). Analisis Framing Pemberitaan Habib Rizieq Shihab selama di RS Bogor Terkait Hasil Swab Test. Jurnal Komunikasi, 15(1), 71-82. doi: https://doi.org/10.21107/ilkom.v15i1.9580
Article History:

Received January, $16^{\text {th }}$ 2021,

Acepted March, 12 2021

(C) 2021 Rain Gunawan, Umaimah wahidsyah 


\section{PENDAHULUAN}

Saat ini hampir seluruh negara di dunia sedang menderita pandemi akibat virus corona dan setiap hari berita tentang Covid-19 terus mengisi berbagai media massa dan media sosial. Laporan dari publikasi Unesco saat peringatan worldpress freedom day bertema-kan "jounalism, press freedom and covid-19", memperlihatkan hasil analis a bahwa ada sekitar 112 juta publikasi di media sosial yang mengupas tentang covid-19, ditemukan sekitar empat puluh persen unggahan berasal dari sumber yang tidak terpercaya. Observatory infodemic foundation juga menemukan 178 tweet terkait covid-19, sebesar empat puluh persen tidak bisa diandalkan kebenarannya. Aliansi

coronavirus membantah sekitar 3.500 informasi yang salah dan menyesatkan tentang covid-19 (Unesco,2020). Seperti publikasi oleh John Zarocostas (world report, 2020: P676), WHO juga menyatakan perang untuk melawan ketidakabsahan informasi seputar covid-19. Direktur Jenderal WHO, Adhanom Ghebreyesus menyatakan bahwa "kita tidak hanya bertarung melawan epidemi, tapi kita juga bertarung melawan infodemic". Disini bisa diasumsikan bahwa seiring banyaknya berita-berita yang muncul dan hadir seiring pandemi covid-19, maka masyarakat diharapkan mampu untuk memilih dan memilah informasi yang benar dan tidak menyesatkan. Disinilah peran media massa sangat besar dalam menyajikan berita yang benar dan terpercaya agar bisa dikonsumsi secara layak oleh masyarakat dan tidak menjerumuskan masyarakat dalam arus informasi yang salah. Berger dan Luckman menyatakan bahwa manusia dan masyrakat merupakan produk yang memiliki pengaruh, dinamis dan plural (Eriyanto, 2012: 17)

Media massa memiliki fungsi untuk memberikan informasi, menghibur, mendidik serta memberi pengaruh kepada publik (to inform, to entertain, to educate, to influence) dan juga sebagai alat atau sarana yang digunakan untuk menyampaikan pesan dari komunikator kepada khalayak (Cangara, 2010). Di Indonesia, kebebasan pers/media massa diatur dalam Undang Undang Pers dan Kode etik jurnalistik (UU no.40 tahun 1999 tentang Pers). Pers terkadang disebut juga sebagai alat fungsi kontrol sosial (watchdog), untuk itu pers seharusnya bertindak sebagai nonpartisipan atau tidak menjadi alat kepentingan tertentu dalam bisnis ataupun dalam bidang politik. Namun dalam realita yang ada saat ini, sebagian besar pers seakanakan menjadi mata dari sekelompok kepentingan kelompok ataupun media penggiringan opini untuk membentuk suatu persepsi di masyarakat dengan tujuan tertentu.

Seperti artikel yang dimuat oleh kompas.com (2020) berjudul RS ummi, MER-C dan Misteri hasil Swab Test Rizieq Shihab dan nusadaily.com (2020) berjudul apa sulitnya RS Ummi jelaskan Habib Rizieq positip atau negatif, dimana kedua media tersebut sama-sama memberitakan tentang sosok HRS yang sedang menjalani perawatan di RS Ummi Bogor. Bahkan, isu tentang HRS yang menjalani perawatandi RS Ummi Bogor ini, menimbulkan polemik yag cukup panjang bahkan sampai masuk ke ranah hukum dengan adanya pelaporan dari ketua satgas covid-19 kota Bogor ke Polresta Bogor.

Seseorang dengan status pasien yang menjalani perawatan di rumah sakit memiliki aspek hukum (legal aspect) terkait hak dan kewajibannya. Begitu juga rumah sakit yang merawat pasien tersebut juga memiliki hak dan kewajiban yang harus di tunaikan. Dikutip dari Diponegoro Law Journal tentang pengaturan perlindungan hukum hak-hak pasien dalam peraturan perundang-undangan tentang kesehatan di Indonesia dinyatakan bahwa hubungan antara pasien, dokter dan rumah sakit tidak hanya bersifat hubungan medik, tapi juga memiliki hubungan hukum (Valeri, Diponegoro law journal, 2017). Untuk itu semua data-data pasien yang tercatat dalam medical record rumah sakit memiliki kekuatan hukum yang tidak bisa di umbar atau di publikasikan begitu saja, tetapi harus dijaga kerahasiaanya dan tidak disalahgunakan demi kepentingan tertentu tapa seijin dari pasiennya. 
Berdasar Undang-Undang No.29 tahun 2004 tentang praktek kedokteran dan Undang - Undang Kesehatan No. 44 tahun 2009, pasien adalah setiap orang yang melakukan konsultasi masalah kesehatannya untuk memperoleh pelayanan kesehatan yang diperlukan, baik secara langsung maupun tidak langsung di Rumah Sakit. Rumah Sakit adalah institusi pelayanan kesehatan yang menyelenggarakan pelayanan kesehatan perorangan secara paripurna yang menyediakan pelayanan rawat inap, rawat jalan, dan gawat darurat. Masing-masing pihak memiliki kewajiban, kewajiban rumah sakit dan kewajiban pasien diatur dengan Peraturan Menteri Kesehatan, yakni Permenkes No.4 Tahun 2018 tentang Kewajiban Rumah Sakit dan Kewajiban Pasien. Peraturan Menteri Kesehatan Republik Indonesia Nomor 4 Tahun 2018 tentang Kewajiban Rumah Sakit dan Kewajiban Pasien ditetapkan oleh Menteri Kesehatan Republik Indonesia Nila Farid Moeloek di Jakarta pada tanggal 12 Februari 2018. Peraturan Menteri Kesehatan Republik Indonesia Nomor 4 Tahun 2018 tentang Kewajiban Rumah Sakit dan Kewajiban Pasien diundangkan oleh Widodo Ekatjahjana, Dirjen Peraturan Perundangundangan Kemenkumham, dan di tempatkan pada Berita Negara Republik Indonesia Tahun 2018 Nomor 416 pada tangal 28 Maret 2018 di Jakarta, agar seluruh orang mengetahuinya. Pasien rumah sakit juga merupakan seorang konsumen, sehingga secara umum pasien juga di lindungi dalam undang-undang No.8 tahun 1999 tentang perlindungan konsumen.

Melihat pentingnya hubungan antara pasien, dokter dan rumah sakit, maka perlu adanya komunikasi kesehatan yang baik. Komunikasi kesehatan yang diterapkan bisa berbasis pada kearifan lokal yang ada agar pesan yang ingin di sampaikan dapat diterima dengan baik oleh penerima pesan. Penelitian Andi Hasan Al Husain dalam Jurnalnya berjudul Komunikasi Kesehatan Dokter dan pasien berbasis kearifan lokal sipakatau di masa pandemi, menyatakan bahwa komunikasi kesehatan dengan berbasis kearifan lokal mampu untuk menggali informasi lebih banyak dalam proses layanan kesehatan dan membuat pasien merasa lebih akrab (Husain, 2020). Bila komunikasi kesehatan tidak terlaksana dengan baik maka bisa terjadi benturan-benturan hubungan yang mengakibatkan konflik yang tidak di inginkan.

Penelitian Heri sungkowo (2018), terkait hak pasien dalam pelayanan rumah sakit juga menyatakan bahwa pemberian informasi tentang hak pasien dalam pelayanan merupakan hal yang sangat penting bagi rumah sakit dan pasien itu sendiri. Dalam standar nasional akreditasi rumah sakit (SNARS), telah di tetapkan bahwa dalam menjaga mutu dan keselamatan pasien, maka setiap rumah sakit harus senantiasa memperhatikan hak pasien di dalam pelayanan. Informasi terkait hak pasien dilakukan sejak pasien masuk sampai dengan pasien selesai menjalani perawatan dan pulang.

Dalam pasal 32 undang-Undang no.44 tahun 2009 tentang rumah sakit, terdapat 18 hak pasien dimana diantaranya adalah mendapatkan privasi dan kerahasiaan penyakit yang di derita termasuk data-data medisnya, memberikan persetujuan atau menolak atas tindakan yang akan di lakukan oleh tenaga kesehatan terhadap penyakit yang di deritanya, memperoleh keamanan dan keselamatan dirinya selama dalam perawatan di rumah sakit, menggugat dan/atau menuntut rumah sakit apabila rumah sakit tidak memberikan pelayanan yang tidak sesuai standar baik secara perdata ataupun pidana. Sedangkan dalam pasal 2 Peraturan Menteri kesehatan Republik Indonesia no.4 tahun 2018 tentang kewajiban rumah sakit terdapat 22 kewajiban rumah sakit yang harus ditunaikan oleh rumah sakit kepada pasien, seperti memberikan informasi yang benar tentang pelayanan Rumah Sakit kepada masyarakat; memberi pelayanan kesehatan yang aman, bermutu, anti diskriminasi, dan efektif dengan mengutamakan kepentingan pasien sesuai dengan standar pelayanan Rumah Sakit; membuat, melaksanakan, dan menjaga standar mutu pelayanan kesehatan di 
Rumah Sakit sebagai acuan dalam melayani pasien; menyelenggarakan rekam medis; memberikan informasi yang benar, jelas dan jujur mengenai hak dan kewajiban pasien; menghormati dan melindungi hak pasien; dan juga keamanan Pasien, pengunjung, dan petugas di Rumah Sakit.

Bila mengacu dari kedua judul berita yang ditulis oleh kompas.com dan daily.com tersebut, tentunya kedua berita tersebut bisa menimbulkan perbedaan persepsi di masyarakat, terlebih bila dikaji lebih jauh dan di kaitkan dengan hak pasien dan kewajiban RS terhadap pasien selama menjalani perawatan di RS. Sosok HRS dengan FPI-nya merupakan salah satu tokoh dan ormas yang ramai diperbincangkan dan menjadi sorotan akhir-akhir ini. Sedangkan RS Ummi ikut menjadi sorotan seiring beredarnya berita HRS menjalani perawatan dan General Check $U p$ di RS tersebut.

Tak dipungkiri, bahwa kehadiran media massa membantu masyarakat untuk mendapatkan informasi yang tidak dialami secara langsung, sehingga membantu kita untuk melihat dunia di sekitar dan membangun realitas. Karena itu media massa dalam memproduksi berita memiliki metode framing yang digunakan untuk membingkai suatu peristiwa. Media massa merupakan agen konstruksi dimana media massa mampu membentuk suatu berita di dasarkan pada penyusunan realitas terhadap suatu peristiwa sehingga bisa memuat cerita atau wacana yang bermakna. Media bukanlah saluran yang bebas, ia juga subjek yang mengkonstruksika $n$ realitas, lengkap dengan pandangan, bias dan keberpihakannya (Eriyanto, 2011:26)

Data Statista 2016 mengungkapkan bahwa masyarakat dalam mengkonsumsi berita terdapat $41 \%$ responden yang mengaku hanya membaca berita dari judulnya saja (tirto.id,2017) Jumlah ini tentu cukup besar. Semakin panjang sebuah artikel berita semakin mungkin berita tersebut tidak dibaca utuh. Maksym Gabielkov dalam jurnalnya berjudul Social clicks: what and who gets read on twitter? Meneliti lebih dari 2,8 juta artikel yang dibagikan di media sosial, 59 persen link berita yang dibagikan tersebut benar-benar tidak di klik sama sekali, ini menandakan bahwa mayoritas artikel atau berita yang dibagi di media sosial tidak berdasar pada proses membaca. Begitupun bila melihat dari kedua judul berita yang disajikan oleh kompas.com dan nusadaily.com tersebut, tentunya dengan judul yang dibuat sedemikian rupa, tanpa membaca isinya pasti akan menimbulkan persepsi yang berbeda-beda di masyarakat. Ada lima kategori berita yang dikenal dalam jurnalistik (Tuchman dikutip oleh Eriyanto, 2012: 126-130) yaitu Hard News, Soft News, Spot News, Developing News, dan Continuing News.

Metode framing sebagai salah satu konsep proses seleksi yang berfungsi untuk menonjolkan aspek tertentu dalam realitas oleh media merupakan satu metode yang banyak di gunakan oleh para jurnalis dalam menulis berita. Analisis framing secara umum sebagai cara untuk mengetahui bagaimana realitas (aktor, kelompok, peristiwa, dan lainlain) dibingkai oleh media (sapahuma, 2012:34-35). Framing adalah membingkai sebuah peristiwa atau dengan kata lain framing digunakan untuk mengetahui bagaimana perspektif atau cara pandang yang digunakan oleh seorang wartawan atau media massa ketika menyeleksi isu dan menulis berita (Sobur,2012). Framing merupakan metode penyajian realitas di mana kebenaran tentang suatu kejadian tidak diingkari secara total, melainkan dibelokkan secara halus, dengan memberikan penonjolan pada aspek tertentu (Anggoro,2014). Penonjolan aspekaspek tertentu dari isu berkaitan dengan penulisan fakta. Ketika aspek tertentu dari suatu peristiwa dipilih, bagaimana aspek tersebut ditulis. Hal ini sangat berkaitan dengan pamakaian diksi atau kata, kalimat, gambar atau foto, dan citra tertentu untuk ditampilkan kepada khalayak. Akibatnya, hanya bagian tertentu saja yang lebih bermakna, lebih diperhatikan, dianggap penting, dan lebih mengena dalam pikiran khalayak. 
Analisis framing sebagai suatu metode analisis teks banyak mendapat pengaruh dari teori sosiologi dan psikologi. Analisis framing termasuk ke dalam paradigma kontruktivis. Paradigma ini memandang realitas kehidupan sosial bukanlah realitas yang natural, tetapi hasil dari konstruksi. Pemikiran konstruksionis diperkenalkan oleh Peter L. Berger yang menyatakan bahwa sebuah realitas hadir di hadapan pembaca setelah melalui sebuah konstruksi (Eriyanto, 2011:15). berita yang muncul merupakan sebuah proses konstruksi dengan suatu peristiwa karena adanya interaksi antara wartawan dengan fakta yang muncul di lapangan (Eriyanto, 2011:18). Dalam penelitiannya, Astutik (2015) menyatakan bahwa berita dan opini akan memandu publik untuk menghubungkan berbagai realitas yang dipisahkan sebelumnya oleh faktor geografis dan psikografis menjadi urutan yang mudah untuk dipahami dan diikuti. Berita adalah informasi. Menurut kontruktivisme, berita merupakan konstruksi yang didasarkan pada bingkai, opini atau sudut pandang dari apa yang dilihat media di lapangan (Eriyanto, 2012: 7). Dua utama esensi dari analis is framing (Eriyanto, 2012: 222) adalah, pertama seleksi dari masalah, sebagai proses dari memilih fakta-fakta dari berbagai realitas. Untuk melihat bagaimana suatu peristiwa yang ditafsirkan dan berhubungan dengan bagian yang ini akan akan ditutupi atau tidak. Kedua, penekanan dimana bagaimana fakta yang ditulis. Penggunaan kata-kata, kalimat dan gambar dari apa yang akan digunakan untuk mendukung penulisan. Bagaimana masalah dipilih, ditulis dan ditampilkan kepada audiens.

\section{Tabel1. Unsur Framing media versi Entman}

\begin{tabular}{|l|l|}
\hline Seleksiisu & $\begin{array}{l}\text { Aspek ini berhubungan dengan } \\
\text { pemilihan fakta. Dari realitas yang } \\
\text { kompleks dan beragam, aspek } \\
\text { mana yang diseleksi untuk di } \\
\text { tampilkan. Dari proses ini selalu } \\
\text { terkandung di dalamnya ada } \\
\text { bagian berita yang dimasukkan } \\
\text { tetapi ada juga berita yang } \\
\text { dikeluarkan. Tidak semua asspek } \\
\text { dari isu ditampilkan. }\end{array}$ \\
\hline
\end{tabular}

\begin{tabular}{|l|l|}
\hline $\begin{array}{l}\text { Penonjolan } \\
\text { aspek dari } \\
\text { isu }\end{array}$ & $\begin{array}{l}\text { Aspek ini berhubungan dengan } \\
\text { penulisan fakta. Ketika aspek } \\
\text { tertentu dari suatu isu tersebut di } \\
\text { pilih, bagaimana aspek tersebut di } \\
\text { tulis. Hal ini sangat berkaitan } \\
\text { dengan pemakaian kata, kalimat, } \\
\text { gambar dan citra tertentu untuk di } \\
\text { tampilkan }\end{array}$ \\
\hline
\end{tabular}

Sumber, Eriyanto, 2011:222

Analisis framing memiliki banyak model, antara lain model Murray Edelman, Robert N. Etman, William A. Gamson maupun Zhongdang Pan dan Gerald $M$. Kosicki. Pada penulisan ini, penulis akan menggunakan analisis framing model Robert $\mathrm{N}$ Etman atau sering disebut framing entman. Model entman bergerak pada level bagaimana peristiwa dipahami dan bagiamana pemilihan fakta yang dilakukan oleh media (sapahuma, 2012:39). Entman melihat framing dalam dua dimensi besar yaitu seleksi isu dan penekanan/penonjolan aspek tertentu dari realitas/isu.

Robert N. Entman adalah salah seorang ahli yang meletakan dasar-dasar bagi analisis framing untuk studi isi media. Konsep framing oleh Entman digunakan untuk menggambarkan proses seleksi dan menonjolkan aspek tertentu dari realitas yang dibangun oleh media massa. Framing dapat dipandang sebagai penempatan informasiinformasi dalam konteks yang khas, sehingga isu tertentu mendapatkan alokasi lebih besar daripada isu yang lain. Selain itu, framing juga memberi tekanan lebih pada bagaimana teks komunikasi ditampilkan dan bagian mana yang ditonjolkan atau dianggap penting oleh pembuat teks. Dengan bentuk seperti itu, sebuah gagasan atau informasi lebih mudah terlihat, lebih mudah diperhatikan, diingat, dan ditafsirkan karena berhubungan dengan skema pandangan khalayak. Analisis framing entmant ini menggambarkan suatu proses seleksi dan bagaimana menonjolkan suatu aspek dari suatu realitas oleh media.

Framing entman memiliki empat elemen yaitu define problem (pedifinisian masalah), diagnose causes (memperkirakan 
penyebab masalah), make moral judgement (membuat pilihan moral) dan treatment recommendation (menekankan penyelesaian konflik) (anggraeni,2018).

\section{Tabel 2. Metode Analisis Framing Entman}

\begin{tabular}{|c|l|}
\hline $\begin{array}{c}\text { Mendefi } \\
\text { nisikan } \\
\text { Masalah }\end{array}$ & $\begin{array}{l}\text { Elemen pertama sebagai master } \\
\text { framing. Di sini, kita bis melihat } \\
\text { bagaimana suatu peristiwa } \\
\text { dipahami. Apakah beritanya positif } \\
\text { atau negatif. }\end{array}$ \\
\hline $\begin{array}{c}\text { Diagnosis } \\
\text { Penyebab }\end{array}$ & $\begin{array}{l}\text { Temukan dan perkirakan sumber } \\
\text { masalahnya. Dimensi iniberusaha atau } \\
\text { berupaya untuk mengetahui } \\
\text { bagaimanacara inidipahami, } \\
\text { terjadidan apa atau siapayangdiangg } \\
\text { ap untuk menjadi yang sumber } \\
\text { penyebabnya. }\end{array}$ \\
\hline $\begin{array}{c}\text { Lakukan } \\
\text { Penilaian } \\
\text { Moral }\end{array}$ & $\begin{array}{l}\text { Penilaian nilai moral yang digunakan } \\
\text { untuk melegitimasi atau berdebat } \\
\text { untuk tindakan atau ide yang sedang } \\
\text { dibuat. }\end{array}$ \\
\hline $\begin{array}{c}\text { Rekomen } \\
\text { dasi } \\
\text { perawatan }\end{array}$ & $\begin{array}{l}\text { Upaya atau solusiapa yang ditawarkan } \\
\text { dan dilakukan untuk menyeles aikan } \\
\text { masalah. } \\
\text { Penyelesaian ini tergantung pada } \\
\text { masalah dan siapa yang menyebabkan } \\
\text { masalah (elemen pertama) }\end{array}$ \\
\hline
\end{tabular}

Sumber: Eriyanto, 2012: 222-224

Terkait dari wacana berita dari kompas.com dan nusadaily.com tersebut, penulis ingin mengkaji bagaimana suatu media melakukan framing dengan menonjolkan sesuatu dan menghilangkan sesuatu agar menarik untuk di baca dan bisa menjadi perhatian netizen. Bagaimana kedua media tersebut menyajikan berita seorang sosok HRS bila ditinjau dan dikaitkan dengan aspek legal seorang pasien ketika berada di RS yaitu terkait dengan hak pasien dan kewajiban RS terhadap pasien. Penulisan ini bertujuan untuk memberikan gambaran pembingkaian baik pemberitaan oleh kompas.com dan nusadaily.com mengenai berita seputar HRS selama di RS ummi Bogor dikaitkan dengan hak pasien dan kewajiban rumah sakit terhadap pasien.

$$
\text { Penelitian serupa dengan }
$$
menggunakan analisis framing sudah banyak dilakukan seperti penelitian yang dilakukan oleh nurul huda (2019) yang mengangkat pemberitaan hoax ratna sarumpaet, dimas bagus laksono (2017) yang mengangkat pemberitaan konflik poso, dan juga andreas rossbach (2017) yang mengangkat pemberitaan mengenai tuduhan peretasan rusia dalam pemilihan presiden Amerika Serikat, namun untuk pemberitaan yang mengangkat tentang kisruh terkait hasil swab HRS selama dirawat di Rumah Sakit UMMI bogor ini belum ditemukan dalam jurnal manapun dan hal ini merupakan kebaruan dari penelitian yang penulis ajukan dengan menggunakan metode framing robert entman.

\section{METODE PENELITIAN}

Penelitian ini menggunakan jenis penelitian kualitatif dengan menggunakan metode analisis framing Robert N. Entman. Kualitatif merupakan penelitian yang berlandaskan pada kata-kata yang tertulis maupun secara lisan dari tindakan yang bis a dilihat. Metode penelitian kualitatif memiliki tujuan untuk menjelaskan fenomena secara mendalam melalui pengumpulan data secara mendalam pula (Krisyantono, 2010:56-57). Pendekatan penelitian ini adalah paradigma konstruktivis karena penelitian ini ingin meneliti berita tentang berita HRS yang dikonstruksikan kedua media tersebut dikaitkan dengan kajian literature terkait dengan hak pasien dan kewajiban RS terhadap pasien sesuai dengan Undang-Undang Kesehatan nomor 44 tahun 2009 dan Peraturan Menteri Kesehatan nomor 4 tahun 2018.

Objek dari penelitian ini adalah berasal dari sumber data teks berita pemberitaan HRS di RS Ummi Bogor pada kompas.com dan nusadaily.com edisi 28 november 2020 dan 7 desember 2020. Sumber data merupakan tempat rujukan yang menjadi pijakan bagi peneliti dalam melakukan penelitian (krisyantono, 2010:41-42). sedangkan Pemilihan kompas.com dan nusadaily.com sebagai obyek penelitian adalah kedua portal berita tersebut sudah 
berskala nasional dengan banyak jaringan di indonesia. Adapun metode pungumpulan data yang dilakukan adalah mengunduh berita/artikel dari kedua portal berita online tersebut sebagai data primer dan juga mencari literature buku-buku dan jurnal yang memiliki kemiripan dengan kasus ini sebagai data sekunder (sugiyono,2010).

Data dianalisa dengan menggunakan 4 elemen model framing Entmen yang meliputi define problem, diagnose causes, make moral judgement dan treatment recomondation. Keabsahan data dalam penelitian ini menggunakan aspek credibility, dimana berita yang ada dikaitkan dengan beberapa sumber berita lain memiliki derajat kepercayaan yang baik, dan aspek transferability yaitu dimana nilai yang berkenaan dengan penelitian ini dapat diterapkan atau digunakan dalam situasi lain dengan kasus yang identik. Penelitian lain yang berkaitan dengan hak pasien dan kewajiban rumah sakit terhadap pasien dapat memanfaatkan data atau informasi dalam penelitian ini karena adanya kesamaan dalam konteks pembahasan.

Penelitian ini hanya terbatas pada analisis dengan menggunakan metode Entman. Pengamatan hanya dilakukan terhadap teks yang ditampilkan oleh media dan kajian literatur yang terkait dengan penelitian ini.

\section{HASIL DAN PEMBAHASAN}

Dipenghujung bulan November 2020, media di Indonesia ramai-ramai memberitakan terkait di rawatnya seorang sosok pentolan Front Pembela Islam (FPI), Habib Rizieq Shihab atau yang sering disebut HRS. Dikutip dari kompas.com, HRS di kabarkan masuk ke Rumah Sakit (RS) Ummi Bogor dikarenakan faktor gejala kelelahan dan akan menjalani general check-up. Berita tentang HRS ini banyak mendapat perhatian dari netizen tanah air karena selain banyak berseliweran di media nasional dan daerah, kabar tentang HRS yang menjalani perawatan di RS Ummi bogor ini juga banyak di akses oleh netizen melalui media sosial seperti twitter ataupun instagram.

Keberadaan HRS di RS Ummi Bogor juga mengundang perhatian Walikota Bogor, Bima Arya yang sekaligus menjadi ketua Satgas Covid-19 kota Bogor. Disinilah polemik muncul, dimana pihak keluarga HRS tidak berkenan untuk melakukan swab test dari satgas covid-19 kota bogor dengan alasan bahwa HRS sudah melakukan swab test dengan pihak MER-C. Tim kuasa hukum FPI juga memberikan surat penolakan resmi akan publikasi hasil pemeriksaan swab HRS. Penolakan test tersebut menyebabkan walikota bogor berang dan mengancam akan datang langsung dan memastikan pemeriksaan swab HRS. Hingga ujung polemik tersebut, ketua Satgas Covid-19 kota bogor melaporkan RS Ummi ke Polresta Bogor dengan dugaan menghambat dan menghalang-halangi proses penanganan penyebaran penyakit menular sesuai UU no.4 tahun 1984.

Kontroversi HRS selama di RS Ummi tidak berakhir sampai disitu. HRS dikabarkan oleh beberapa media dengan kalimat "kabur dari rumah sakit lewat pintu belakang atau gudang obat", namun ada juga beberapa media yang menulis dengan kalimat "minta pulang atau di izinkan pulang". Terkait dengan berita penolakan swab test dan publikasinya, beberapa media yang menulis antara lain kompas.com "Buntut masalah tes swab Rizieq Shihab, Dirut RS Ummi dilaporkan ke Polisi", nusadaily.com "apa sulitnya RS Ummi jelaskan Habib Rizieq positip atau negatif", detiknews "Dirut dipolisikan terkait hasil swab tes HRS, ini respons $R S$ Ummi" di kompas.com juga muncul berita lain dengan judul "RS Ummi, Mer-C dan Misteri hasil Swab test Rizieq Shihab' dan masih banyak yang lain. Sedangkan untuk berita kepulangan HRS, media yang menulis untuk klarifikasi "kabur" antara lain okezone.com "Satpam RS Ummi: HRS bukan kabur, tapi menghindar sorot media", suara.com "Disebut kabur, Habib Rizieq: Saya minta pulang dari RS Ummi Bogor", bisnis.com "Dirut RS ummi: Habib 
Rizieq shihab pulang atas permintaan sendiri" sedangkan suarajakarta.id menulis judul "Habib Rizieq kabur lewat gudang obat rumah sakit RS Ummi Bogor"

Dari beberapa berita yang muncul tersebut, penulis bermaksud mengkaji berita dari kompas.com berjudul "RS Ummi, Mer-C dan Misteri hasil Swab test Rizieq Shihab" dan dari nusadaily.com dengan judul "apa sulitnya RS Ummi jelaskan Habib Rizieq positip atau negatif" dengan menggunakan analisis framing.

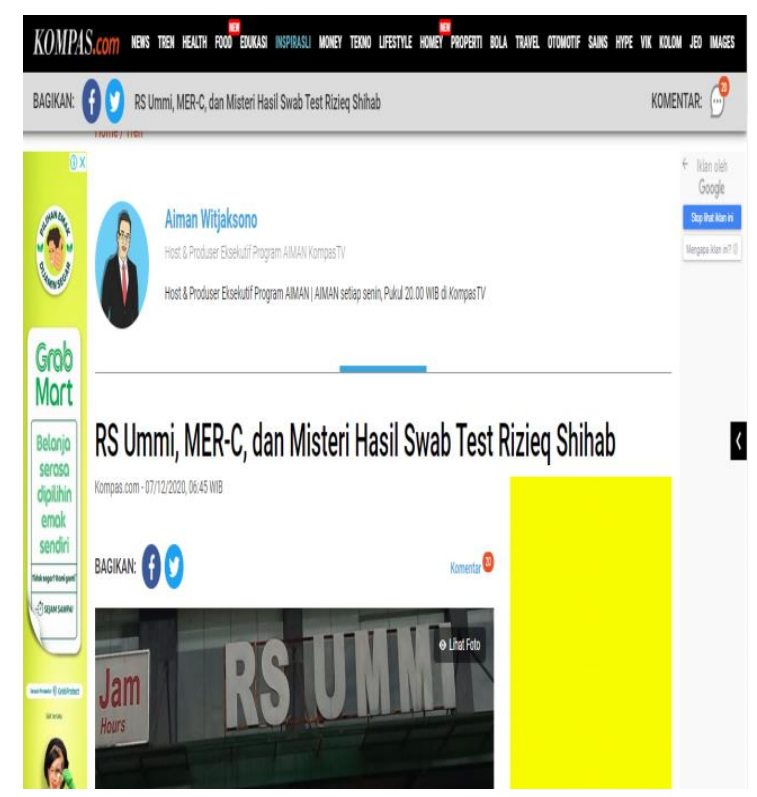

Gambar 1. Berita k ompas.com

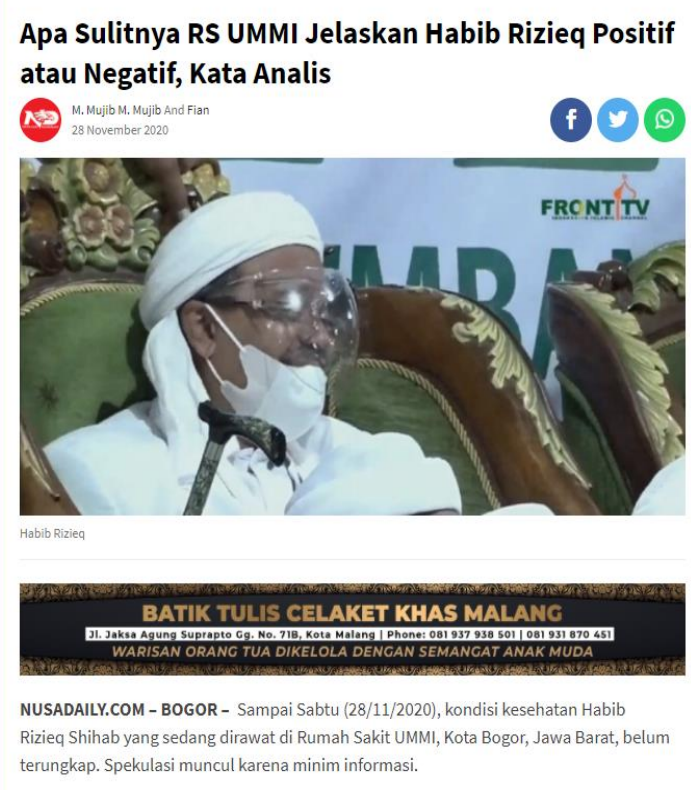

Gambar 2. Berita nusadaily.com
Tabel 3. Analisis model Framing Entman

\begin{tabular}{|c|c|}
\hline \multicolumn{2}{|c|}{$\begin{array}{l}\text { Elemen Framing Entman : } \\
\text { Definisi permasalahan (define problem) }\end{array}$} \\
\hline $\begin{array}{l}\text { Temuan } \\
\text { di media }\end{array}$ & $\begin{array}{l}\text { Adanya pemberitaan terkait sosok HRS } \\
\text { yang menjalani perawatan di rumah sakit } \\
\text { ummi bogor dan kis ruh terkait hasil swab } \\
\text { test }\end{array}$ \\
\hline Analis a & $\begin{array}{l}\text { Media memberitakan terkait sosok HRS } \\
\text { yang menjalani general check up dan } \\
\text { perawatan di RS Ummi bogor karena } \\
\text { faktorkelelahan. halinidikaitkan aktifitas } \\
\text { HRS yang begitu padat setiba } \\
\text { kepualanganya ke tanah air. Seiring } \\
\text { perkembangan informasi, bahwa HRS } \\
\text { dicurigai terkena positif covid-19 maka } \\
\text { pihak satgas covid-19kota bogor meminta } \\
\text { rumah sakit ummi untuk melakukan swab } \\
\text { test kepada yang bersangkutan, namun hal } \\
\text { ini di tolakoleh pihak keluarga pasien dan } \\
\text { kuasa hukum pasien karena pasien sudah } \\
\text { melaksanakan swab test melalui bantuan } \\
\text { MER-C. Disinilah konflik mulai muncul. } \\
\text { Dan pihak RS juga tidak mau membuka } \\
\text { data hasil swab pasien. }\end{array}$ \\
\hline \multicolumn{2}{|c|}{$\begin{array}{l}\text { Elemen Framing Entman : } \\
\text { Memperkirakan masalah/sumber masalah } \\
\text { (diagnose causes) }\end{array}$} \\
\hline $\begin{array}{r}\text { Temuan } \\
\text { di media }\end{array}$ & $\begin{array}{l}\text { adanya penolakan dari pihak pasien } \\
\text { (dalam hal ini keluarga HRS dan kuasa } \\
\text { hukum HRS) untuk melakukan swab test } \\
\text { dan penolakan dari pihak rumah sakit } \\
\text { ummi untuk membuka data hasil s wab test } \\
\text { HRS ke satgas covid-19kota bogor }\end{array}$ \\
\hline Analisa & $\begin{array}{l}\text { Bila mengacu pada peraturan perundangan } \\
\text { no } 44 \text { tahun } 2009 \text { tentang hak pasien } \\
\text { selama di rawat dirumah sakit, memang } \\
\text { pasien di perbolehkan untuk tidak } \\
\text { menyetujui tindakan medis atau tindakan } \\
\text { lain yang menurut pihak pasien bisa } \\
\text { merugikan dirinya. Dan hal ini bila di } \\
\text { langgar oleh rumah sakit, maka pasien } \\
\text { juga berhak untuk melakukan pelaporan } \\
\text { dan penuntutan baik secara perdata } \\
\text { ataupun pidana ke pengadilan. Di pihak } \\
\text { RS, sebagaiamanah yang tercantumdalam } \\
\text { UU no.4 tahun 2018, bahwa rumah sakit } \\
\text { berkewajiban melindungi hak pasien dan } \\
\text { berkewajiban menyelenggarakan rekam } \\
\text { medik (medical record) yang baik dimana } \\
\text { rekam medik ini memiliki kekuatan } \\
\text { hukumdan bersifat rahasia. } \\
\text { Tentunya hal ini menimbulkan masalah } \\
\text { karena pihak satgas covid-19 kota bogor } \\
\text { bersikeras kepada RS untuk mendapatkan } \\
\text { hasilswab testpasien dengan alasan untuk } \\
\text { kebutuhan tracing. Sedangkan RS tidak } \\
\text { berkenan untuk membuka data pasien. }\end{array}$ \\
\hline
\end{tabular}




\begin{tabular}{|c|l|}
\hline \multicolumn{1}{|c|}{} & $\begin{array}{l}\text { Dan halini mengakibatkan RS dilaporkan } \\
\text { ke polresta bogor karena dianggap } \\
\text { menghalangi upaya penanganan wabah } \\
\text { covid-19. }\end{array}$ \\
\hline Elemen Framing Entman: \\
Membuat keputusan moral \\
(make moraljudgement) \\
Ti media
\end{tabular}

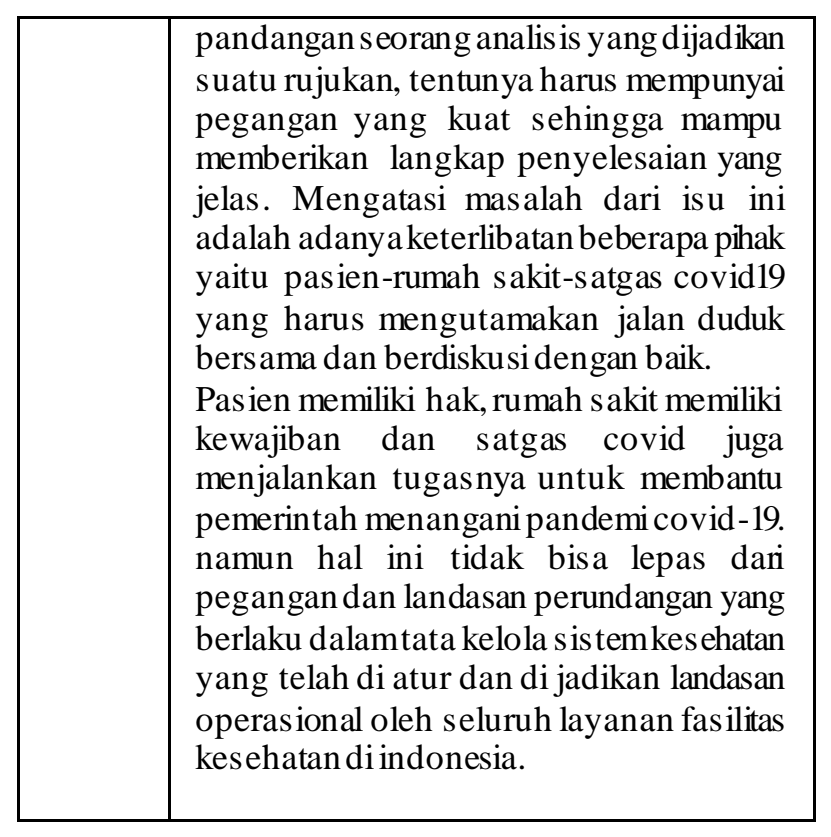

Bila di lihat dari judul kedua berita online tersebut, dapat terlihat bahwa terdapat perbedaan gaya penulisan yang digunakan oleh kompas.com dan nusadaily.com. Judul berita oleh Kompas.com bisa dibilang tidak begitu kontroversial dibandingkan judul yang ditulis oleh nusadaily.com. Kompas.com dengan judul berita RS Ummi, Mer-C dan Misteri hasil swab test Rizieq Shibah membingkai berita dengan penekanan hubungan rs ummi, mer-c, dan kisruh walikota bogor bima arya selaku ketua satgas covid-19 kota bogor dengan pihak HRS terkat hasil swab test, namun penyajian berita oleh kompas.com cukup detail karena menyajikan sisi argumentatif dan alasan terkait dasar dari penolakan pembukaan informasi data pasien HRS tersebut dikaitkan dengan Undangundang yang berlaku dan narasumber dari Ketua Konsil Kedoteran Indonesia. Sedangkan nusadaily.com dengan judul berita apa sulitnya, RS Ummi jelaskan habib rizieq positif atau negatif, lebih cenderung menekankan baik berita dan judul berita melalui sisi dan segi pandang seorang analis politik. Tentunya hal ini bila diteliti lebih jauh maka seharusnya kontributor dari nusadaily.com mengambil narasumber seorang analis kesehatan atau orang yang ahli dalam hukum kesehatan sehingga bisa memberikan pandangan yang obyektif terhadap kasus yang ada. Pemberitaan dari 
nusadaily.com juga tidak diberikan landasan lebih lanjut terkait hak seorang pasien di rumah sakit dan apa kewajiban rumah sakit terhadap pasien yang sedang menjalani perawatan di rumah sakit. Tidak bisa di pungkiri bahwa media dalam menyajikan suatu berita tidak lepas dari unsur headline atau berita yang menarik sehingga orang akan tertarik untuk membaca artikelnya. Namun perlu juga kiranya di kaji bahwa bila mengangkat suatu berita dengan pijakan dan landasan teori dan hukum yang tepat serta pilihan narasumber yang bagus akan memberikan kwalitas berita semakin bagus dan informasi yang diterima oleh pembaca juga menjadi benar adaya.

Bila di kaji dengan menggunakan 4 elemen model framing entman ditemukan identifikasi sebagai berikut; pada aspek define problem, kompas.com dan nusadaily.com sama-sama menyajikan berita terkait HRS yang sedang menjalani perawatan di RS Ummi Bogor, polemik seputar hasil swab test HRS dan penolakan RS Ummi untuk membuka data tersebut. Kompas.com mengulas keterkaitan antara pihak HRS MerC - RS Ummi Bogor - Satgas Covid kota bogor - Konsil Kedokteran Indonesia terkait polemik swab test. Sedangkan nusadaily.com mengulas keterkaitan pihak HRS - RS Ummi Bogor - Analis Politik terkait swab test. Segi pandang ulasan keterkaitan ini yang membuat isi berita yang disajikan kedua media online ini menjadi berbeda. Kompas.com lebih lengkap dalam mengulas sisi ini dibandingkan dengan nusadaily.com.

Pada aspek diagnose causes, sumber masalah berada pada pihak HRS yang tidak mau melaksanakan swab test bersama satgas covid-19 kota bogor dan pihak RS ummi Bogor yang tidak mau membuka data hasil swab test HRS. Disinilah, ulasan dari kompas.com menyajikan ulasan yang cukup detail dengan menggunakan pijakan UU no.44 tahun 2009 dan UU no. 4 tahun 2018 pada beritanya. Bahkan kompas.com juga menyajikan informasi dari ketua konsil kedokteran indonesia untuk mempertajam berita yang disajikan. Sementara nusadaily.com menyajikan ulasan yang kurang detail dan menggunakan sumber masukan dari analis politik dimana sepatutnya sumber masukan adalah dari orang yang berkecimpung dalam bidang kesehatan sehingga bisa mengetahui alasan mengapa pihak pasien dan pihak rumah sakit tidak bersedia membuka data hasil swab tersebut.

Pada aspek make moral judgement, dapat dilihat bahwa kompas.com mempertimbangkan sisi hukum atas ulasannya dengan menggunakan pijakan perundangan yang berlaku sehingga mampu memberikan informasi yang baik bagi para pembacanya. Sedangkan nusadaily.com lebih kepada pandangan seorang analis politik dalam pembukaan data pasien dimana seyogyanya hal ini tidak tepat untuk di kemukakan. Moral yang dapat diambil disini adalah, perlunya penyajian berita yang komprehensif dengan penggunaan pijakan yang sesuai dengan kasus yang ada, perlunya narasumber yang kompeten untuk di kaitkan dengan isu yang berkembang sehingga isi dan nilai berita lebih terintegrasi.

Pada aspek treatment recomendation, penyelesaian yang ditawarkan oleh kompas.com mengacu pada perundangan yang ada dan masukan dari konsil kedokteran indonesia bahwa pasien memiliki hak dan rumah sakit memiliki kewajiban yang perlu di tunaikan kepada pasien. Namun ada hal pengecualian dalam kasus-kasus tertentu. Sedangkan nusadaily.com mengemukakan penyelesain sesuai informasi dari analis politik bahwa data pasien di buka saja karena tidak ada susahnya (tanpa mempedulikan hak pasien dan kewajiban RS terhadap pasien). Berita yang disajikan lebih terperinci dengan pertimbangan unsur-unsur yang terkait dan rujukan yang tepat, diharapkan mampu memberikan informasi yang produktif dan memiliki nilai informasi yang benar.

\section{PENUTUP}

Dari analisis framing robert entman tersebut diatas dapat ditarik kesimpulan 
bahwa kedua media dalam menyajikan berita memiliki gaya dan teknik penulisan yang berbeda dalam menggaet pembaca untuk mau membaca berita yang di sajikannya. Berkaca dari berita yang diangkat kedua media terkait pemberitaan HRS selama di rawat di rumah sakit ummi bogor, perlu kiranya di tinjau lebih jauh dan di analisis dengan menggunakan pijakan dan landasan yang berlaku seperti undang-undang.

Bila di kaji lebih jauh berdasarkan undang-undang kesehatan dan undangundang tentang kewajiban rumah sakit, maka isu ini bisa tercover dengan baik. Dimana media menuliskan berita terlebih dulu mengaitkannya dengan kedua landasan hukum tersebut. Memang tidak bisa di pungkiri bahwa media menekankan sebuah judul berita untuk menarik minat pembaca namun juga harus memperhatikan sisi atau nilai positif yang bisa di persepsikan oleh pembaca untuk menarik kesimpulan dari berita yang di sajikan tersebut.

\section{DAFTAR PUSTAKA}

Anggraeni, Diana. 2018.. Entman Framing Analysis of Food Governance in Onnline Media. Jurnal The Messenger, Vol. 10, No. 1, 113-123

Anggoro, Ayub Dwi. 2014. Media, Politik dan Kekuasaan (Analisis Framing Model Robert N. Entman tentang pemberitaan hasil pemilihan presiden, 9 juli 2014 di TV One dan Metro TV), JurnalAristo Vol 2 No 2, 25-52

Astutik, P.W. 2015. Framing Pemberitaan Citra Politik Capres 2014 di harian solopos. Jurnal the messenger,7 (2), 9-17

Cangara, Hafied. 2010. Pengantar Ilmu Komunikasi, Jakarta, PT Raja Grafindo Jakarta
Eriyanto. 2011. Analisis Framing: Konstruksi

Ideologi dan Politik Media, Yogyakarta: Lkis

Eriyanto. 2012. Analisis Framing: Konstruksi, Ideologi dan Politik Media. Yogyakarta: LKiS

Habibie, Didi Kusuma. 2018. Dwi Fungsi Media Massa. Interaksi Jurnal Komunikasi, Vol.7, No.2

Husain, Andi Hasan. 2020. Komunikasi Kesehatan Dokter dan Pasien Berbasis Kearifan Lokal Sipakatau di Masa Pandemi. Jurnal Ilmu Komunikasi, Vol 18, No.2 Hal 126141

Krisyantono, rachmat. 2010. Teknik Praktis Riset Komunikasi: Disertasi contoh praktis riset media, public relations, advertising, komunikasi organisasi, komunikasi pemasaran, Edisi 1 . Jakarta: kencana pranada media group

Kementerian Kesehatan Republik Indonesia. 2018. Peraturan Menteri Kesehatan Republik Indonesia No.4 Tahun 2018 tentang Kewajiban Rumah Sakit dan Kewajiban Pasien

Kementerian Kesehatan Republik Indonesia. 2017. Peraturan Menteri Kesehatan Republik Indonesia Nomor 1691/MENKES/PER/VIII/2011

Tentang Keselamatan Pasien Rumah Sakit, Standar Nasional Akreditasi Rumah Sakit, edisi 1, KARS.

Mujib, M. 2020. Apa sulitnya RS Ummi jelaskan Habib Rizieq positip atau negatif, Kata Analis, diakses dari https://nusadaily.com/metro/apasulitnya-rs-ummi-jelaskan-habibrizieq-positif-atau-negatif-kataanalis.html 
Sapahuma, Nacota Yeshida. 2015. Realitas Politik dalam media massa (Konstruksi pemberitaan media massa seputar 100 hari pemerintahan Jokowi-JK), Politika: Jurnal ilmu politik, Vol6, No.1, Hal 82-92

Siringoringo, Valeri M.P. 2017. Pengaturan Perlindungan Hukum Hak Pasien Dalam peraturan PerundanganUndangan tentang kesehatan di Indonesia. Diponegoro Law Jorunal, Vol 6, No.2 Hal 1-13

Sobur, A. 2012. Analisis Teks Media. Bandung: Remaja Rosdakarya

Sungkowo, Heri. 2018. Efektifitas pemberian informasi hak pasien dalam pelayanan di rumah sakit islam fatimah cilacap. Jurnal Ekonomi, Bisnis, dan Akuntansi, Vol 20, No.2 Hal 1-7

UNESCO. 2020. Journalism, press freedom and COVID-19: World Trends in Freedom of Expression and Media Development. https://en.unesco.org/sites/default/fil es/unesco_covid_brief_en.pdf
Undang-undang Republik Indonesia Nomor 8 Tahun 1999 tentang Perlindungan Konsumen.

Undang-undang Republik Indonesia Nomor 44 Tahun 2009 tentang Rumah Sakit.

Undang-undang Republik Indonesia Nomor 29 Tahun 2004 tentang Praktek Kedokteran.

Witjaksono, Aiman. 2020. RS ummi, MER-C dan Misteri hasil Swab Test Rizieq Shihab, diakses dari https://www.kompas.com/tren/read/ 2020/12/07/064500565/rs-ummimer-c-dan-misteri-hasil-swab-testrizieq-shihab? page $=$ all

Zarocostas, J. 2020. How to fight an infodemic, Lancet (London, England). DOI: https://doi.org/10.1016/S01406736(20)30461-X.

Zaenudin, Ahmad. 2017. Mengonsumsi Informasi dari Hanya Membaca Judul.

Diaksesdarihttps://tirto.id/mengonsu msi-informasi-dari-hanyamembaca-judulcwx5 